\title{
EGFR pathway biomarkers in erlotinib-treated patients with advanced pancreatic cancer: translational results from the randomised, crossover phase 3 trial AIO-PK0104
}

\begin{abstract}
S Boeck ${ }^{*}, 1$ A Jung ${ }^{2}, \mathrm{R}$ P Laubender ${ }^{3}, \mathrm{~J}$ Neumann ${ }^{2}, \mathrm{R}$ Egg ${ }^{1,2}, \mathrm{C}$ Goritschan ${ }^{1,2}, \mathrm{U}$ Vehling-Kaiser ${ }^{4}$, C Winkelmann ${ }^{5}$, L Fischer von Weikersthal ${ }^{6}$, M R Clemens $^{7}$, T C Gauler $^{8}$, A Märten ${ }^{9}$, S Klein ${ }^{10}$, G Kojouharoff ${ }^{11}$, M Barner ${ }^{12}$, M Geissler ${ }^{13}$, T F Greten ${ }^{14}$, U Mansmann ${ }^{3}$, T Kirchner ${ }^{2}$ and V Heinemann ${ }^{1}$

${ }^{1}$ Department of Internal Medicine III and Comprehensive Cancer Center, Klinikum Grosshadern, Ludwig-Maximilians-University of Munich, Marchioninistr 15, Munich D-81377, Germany; ${ }^{2}$ Department of Pathology, Ludwig-Maximilians-University of Munich, Munich, Germany; ${ }^{3}$ Institute of Medical Informatics, Biometry and Epidemiology, Ludwig-Maximilians-University of Munich, Munich, Germany; ${ }^{4}$ Practice for Medical Oncology, Landshut, Germany; ${ }^{5}$ Department of Internal Medicine, Krankenhaus Lutherstadt-Wittenberg, Lutherstadt-Wittenberg, Germany; ${ }^{6}$ Department of Oncology, Gesundheitszentrum St Marien GmbH, Amberg, Germany; ${ }^{7}$ Department of Internal Medicine I, Klinikum Mutterhaus Trier, Trier, Germany; ${ }^{8}$ Department of Medicine (Cancer Research), West German Cancer Center, University of Duisburg-Essen, Essen, Germany; ${ }^{9}$ Department of Surgery, University of Heidelberg, Heidelberg, Germany; ${ }^{10}$ Department of Internal Medicine IV, Klinikum Bayreuth, Bayreuth, Germany; ${ }^{11}$ Practice for Medical Oncology, Darmstadt, Germany; ${ }^{12}$ Department of Internal Medicine, Evangelisches Krankenhaus Köln-Weyertal, Köln, Germany; ${ }^{13}$ Department of Gastroenterology and Oncology, Klinikum Esslingen, Esslingen, Germany and ${ }^{14}$ Department of Gastroenterology, Hepatology and Endocrinology, Medical School Hannover, Hannover, Germany
\end{abstract}

Background: We aimed to identify molecular epidermal growth factor receptor (EGFR) tissue biomarkers in pancreatic cancer (PC) patients treated with the anti-EGFR agent erlotinib within the phase 3 randomised AIO-PK0104 study.

Methods: AlO-PK0104 was a multicenter trial comparing gemcitabine/erlotinib followed by capecitabine with capecitabine/erlotinib followed by gemcitabine in advanced PC; primary study end point was the time-to-treatment failure after first- and second-line therapy (TTF2). Translational analyses were performed for KRAS exon 2 mutations, EGFR expression, PTEN expression, the EGFR intron 1 and exon 13 R497K polymorphism (PM). Biomarker data were correlated with TTF, overall survival (OS) and skin rash.

Results: Archival tumour tissue was available from 208 (74\%) of the randomised patients. The KRAS mutations were found in $70 \%$ (121 out of 173) of patients and exclusively occurred in codon 12. The EGFR overexpression was detected in 89 out of 181 patients (49\%) by immunohistochemistry (IHC), and 77 out of 166 patients (46\%) had an EGFR gene amplification by fluorescence in-situ hybridisation (FISH); 30 out of 171 patients (18\%) had a loss of PTEN expression, which was associated with an inferior TTF1 (firstline therapy; HR 0.61, $P=0.02$ ) and TTF2 (HR 0.66, $P=0.04)$. The KRAS wild-type status was associated with improved OS (HR 1.68, $P=0.005)$; no significant OS correlation was found for EGFR-IHC (HR 0.96), EGFR-FISH (HR 1.22), PTEN-IHC (HR 0.77), intron 1 (HR 0.91) or exon 13 R497K PM (HR 0.83). None of the six biomarkers correlated with the occurrence of skin rash.

Conclusion: The KRAS wild-type was associated with an improved OS in erlotinib-treated PC patients in this phase 3 study; it remains to be defined whether this association is prognostic or predictive.

*Correspondence: Dr S Boeck;

E-mail: stefan.boeck@med.uni-muenchen.de

Previous presentation: 35th ESMO Congress, 8-12 October 2010, Milan,

Italy and 47th ASCO Annual Meeting, 3-7 June 2011, Chicago, IL.

Received 30 August 2012; revised 15 October 2012; accepted 16 October 2012; published online 20 November 2012

(c) 2013 Cancer Research UK. All rights reserved 0007-0920/13 
During the last decade, several molecular agents targeting different pathways have been investigated for the treatment of patients with advanced pancreatic cancer (PC) (Stathis and Moore, 2010). However, only the oral epidermal growth factor receptor (EGFR) tyrosine kinase inhibitor erlotinib has shown a statistically significant (but clinically moderate) OS benefit when added to standard chemotherapy with gemcitabine in a large randomised phase 3 trial (Moore et al, 2007; Stathis and Moore, 2010). Erlotinib is a small molecule that targets the erbB1/HER1 receptor (EGFR) by inhibiting intracellular receptor transphosphorylation, thereby blocking downstream signal transduction pathways such as the PI3K-AKT-PTEN network or the RAS-RAF-MAPK-MEKERK cascade ( $\mathrm{Ng}$ et al, 2002).

In advanced PC, several clinical (e.g. stage of disease or performance status) and biochemical (e.g. serum tumour marker CA 19-9) factors with a prognostic significance have already been identified (Boeck et al, 2007, 2010). In contrast, validated molecular prognostic markers or even predictive biomarkers for the treatment efficacy of biological agents (such as erlotinib or cetuximab) are still lacking in PC. All phase 3 trials investigating biologicals in PC have included unselected patient populations and up to now, only limited data have been published on translational substudies from large multicenter phase 3 trials. In other disease entities such as colorectal cancer (CRC) or non-small-cell lung cancer (NSCLC) - where anti-EGFR treatment strategies also have been studied widely-several predictive biomarkers for agents such as cetuximab, panitumumab, erlotinib or gefitinib were identified including mutations in the KRAS gene, activating mutations in EGFR exons 18 to 21 as well as the EGFR expression level (Heinemann et al, 2009; Heist and Christiani, 2009; Pirker et al, 2012). In advanced PC, only the authors of the erlotinib pivotal PA.3 trial $(n=569)$ recently reported a translational biomarker analysis on KRAS mutation $(n=117)$ and EGFR gene copy number $(n=107)$ in a subset of their study patients. Within this post-hoc analysis, neither KRAS mutational status nor the EGFR gene copy number was predictive for a survival benefit from the combination of gemcitabine plus erlotinib (Da Cunha Santos et al, 2010).

Previous reports investigating potential prognostic and/or predictive molecular biomarkers of the EGFR pathway in PC were mainly derived from small, often retrospective single-centre studies and not from prospective randomised trials (Immervoll et al, 2006; Lee et al, 2007; Tzeng et al, 2007b; Chen et al, 2010). In those studies, the presence of a KRAS codon 12 mutation was found to be a negative prognostic factor (Lee et al, 2007; Chen et al, 2010), whereas an increased EGFR gene copy number did not seem to have an impact on OS (Lee et al, 2007; Tzeng et al, 2007b). Of note, the incidence of activating mutations in exon 18-21 of the EGFR gene as well as in the BRAF proto-oncogene seemed to be very low $(<2 \%)$ in pancreatic ductal adenocarcinoma (Immervoll et al, 2006; Lee et al, 2007). The tumour-suppressor gene and AKT-inhibitor PTEN may also have a role in the sensitivity to anti-EGFR agents, as suggested by several translational analyses from metastatic CRC (Loupakis et al, 2009). In PC, no data on the prognostic or predictive role of PTEN (specifically in patients receiving anti-EGFR treatment) have been reported to date.

Other groups focused on the investigation of EGFR gene polymorphisms that may regulate the EGFR gene transcription level and also could have a prognostic and/or predictive impact on outcome parameters. In addition, hypothesis-generating data suggest that EGFR gene polymorphisms may also be associated with the occurrence of skin rash, an important side-effect of antiEGFR treatment known to correlate with survival. In pre-clinical and early clinical studies, a highly polymorphic CA dinucleotide repeat in the intron 1 of the EGFR gene was found to have a prognostic role after PC surgery, to mediate in-vitro response to erlotinib, and to correlate with the occurrence of skin rash (Amador et al, 2004; Tzeng et al, 2007a; Huang et al, 2009; Frolov et al, 2010; Klinghammer et al, 2010). In addition, for the R497K $\mathrm{PM}$ in exon 13 of the EGFR gene a prognostic role was previously suggested in patients with CRC and NSCLC (Wang et al, 2007; Sasaki et al, 2009).

The aim of this explorative translational biomarker study based on the prospective AIO-PK0104 trial was: first, to assess the feasibility of translational research in PC multicenter phase 3 studies; second, to determine the frequency of alterations of components of the EGFR pathway and of EGFR gene polymorphisms within the study population and third, to correlate biomarker data with the efficacy (time-to-treatment failure and OS) and safety end points (skin rash) from the clinical data set.

\section{MATERIALS AND METHODS}

Translational patient population. For the AIO-PK0104 phase 3 trial adult patients (aged 18-75 years) with a histologically or cytologically confirmed diagnosis of treatment-naïve, advanced, exocrine PC (stage III and IV) were eligible. Overall, 281 patients were randomised and 274 patients were classified eligible for the intention-to-treat (ITT) population (Heinemann et al, 2012). Archival formalin-fixed paraffin-embedded (FFPE) tissue, which was obtained during routine diagnostic procedures, was requested retrospectively from the participating centres/pathologists for this translational study. Cytological specimens were not suitable for this analysis. The FFPE histological tissue was accepted independent of its origin, for example surgical or biopsy specimens from primary pancreatic tumour, lymph nodes or distant metastases. The study had approval of the ethical committees in all participating German centres and patients gave written informed consent before any study-specific procedure. This study was conducted according to GCP/ICH guidelines and according to the Declaration of Helsinki and was registered at ClinicalTrials.gov, number NCT00440167.

Analyses of molecular tissue biomarkers. The translational analyses from AIO-PK0104 were performed centrally at the University of Munich, Department of Pathology (Max-Borst Laboratory for Cancer Research) by JN, AJ and TK. All obtained FFPE tumour blocks were checked for quality, tissue integrity and tumour content (HE staining) by a pathologist (JN) in a blinded manner. Tumour tissue was enriched by hand-guided microdissection using scalpel blades. Genomic DNA was extracted using QIAamp DNA FFPE micro or DNAeasy micro Kits (Qiagen, Hilden, Germany) according to the manufacturer's instructions. Such DNA was used as a template in PCRs together with Hot Star Taq DNA Polymerase (Qiagen) and gene-specific primers (Supplementary Table S1).

KRAS exon 2 mutation. Mutations in codons 12 and 13 of the KRAS proto-oncogene were investigated by pyrosequencing using KRAS exon 2-specific primers and PyroMark Gold kits (Qiagen). Pyrosequencing was performed employing a PyroMark Q24 device (Qiagen) as described previously (Neumann et al, 2009).

Epidermal growth factor receptor expression. Protein expression of the EGFR was analysed using a monoclonal mouse anti-EGFR antibody (pre-diluted CONFIRM EGFR antibody, clone 5B7; Ventana Medical Systems, Tucson, AZ, USA) and was performed on a Ventana Benchmark XT autostainer using the XT UltraView diaminobenzidine kit (Ventana Medical Systems). EGFR-IHC (immunohistochemistry) scoring (0-3) was performed blinded by $\mathrm{JN}$ and RE based on a previously published score for PC (Ueda et al, 2004). The following staining parameters were taken into 
account: percentage of positive cells, membrane or cytoplasmic staining, complete or incomplete staining. For this study, only samples with a score of 2 or 3 were judged as EGFR-IHC positive (Ueda et al, 2004).

The EGFR gene amplification was analysed by fluorescence in-situ hybridisation (FISH) assays, which were carried out on $4 \mu \mathrm{m}$ tissue sections containing representative tumour cells. The FISH assay was performed with the SPEC EGFR/CEN 7 Dual Color Probe (Zytovision, Bremerhaven, Germany) according to the manufacturer's instructions. Analyses were done by one observer (RE) using a fluorescence microscope: a minimum of 100 tumour cell nuclei was scored according to the number of green (EGFR gene) and red (centromere region of chromosome 7) signals observed and grouped into six different categories (Cappuzzo et al, 2005; Da Cunha Santos et al, 2010). Samples with polysomy high or amplification were regarded as EGFR-FISH positive.

The PTEN expression. For the PTEN-IHC analyses, a monoclonal mouse anti-human PTEN antibody was used (clone 6H2.1; DAKO, Hamburg, Germany). After heat-induced epitope retrieval using Pro Taqs IV Antigen Enhancers (Quartett, Berlin, Germany) the primary antibody was incubated for $1 \mathrm{~h}$ at a dilution of $1: 30$. The slides were then washed and subsequently developed by addition of the detection system (ImmPRESS Reagent Kit Anti-MOUSE Ig, Vector Laboratories, Burlingame, CA, USA). The AEC + system (DAKO) was used as chromogen and the slides were then counterstained with hematoxylin (Vector Laboratories). To exclude nonspecific staining, system controls were included. As there are still no validated scoring systems to interpret staining for PTENIHC in PC, we adopted a score developed by Loupakis et al (2009) in CRC. For the PTEN-IHC scoring of 0-6 (performed blinded by $\mathrm{JN}$ and $\mathrm{CG}$ ), the two parameters percentage of positive tumour cells and staining intensity were selected as described previously (Loupakis et al, 2009). Samples were defined as PTEN-IHC positive if the score was $\geqslant 4$.

EGFR gene polymorphism (intron 1 and exon 13). The (CA) polymorphism found in intron 1 of the EGFR as well as the R497K $(\mathrm{G}>\mathrm{A})$ PM in exon 13 of the EGFR were investigated by subjecting PCR products to restriction fragment length polymorphism analysis on a Genetic Analyzer 3130 (Applied Biosystems, Darmstadt, Germany) (intron 1) and by pyrosequencing on a Pyromark Q24 device (Qiagen) (exon 13) (Wang et al, 2007; Tzeng et al, 2007a). For the statistical correlation the number of CA repeats was determined for both alleles separately but also the sum of both repeat numbers was calculated (Tzeng et al, 2007a; Frolov et al, 2010). For the EGFR exon 13 R497K PM, homozygous $\mathrm{G}$ on both alleles (Arg/Arg) was scored as wild-type sequence, whereas heterogeneous GA (Arg/Lys) or homogeneous A (Lys/Lys) on the two alleles were classified to be single-nucleotide polymorphisms (SNP) (Wang et al, 2007).

Statistical analyses. All statistical analyses for the translational study of the AIO-PK0104 trial were performed centrally at the University of Munich, Institute of Medical Informatics, Biometry and Epidemiology by RPL and UM. Translational biomarker data were correlated with efficacy (time-to-treatment failure and OS) and safety study end points (skin rash) using univariate analyses. As appropriate, biomarker results were handled as dichotomous (e.g. KRAS mutation, EGFR-FISH positive $v s$ EGFR-FISH negative) or continuous variables (e.g. linear-scoring system 0-6 for PTEN-IHC). Time-to-event end points were analysed with the Kaplan-Meier method; differences were compared using the logrank test with a two-sided $P$-value of $<0.05$ being regarded as statistically significant.

\section{RESULTS}

Patient characteristics. The FFPE tumour blocks were available from 208 of the 281 randomised patients (74\%). The main reasons for not obtaining FFPE tissue in the remaining 73 cases were missing tissue according to the study centre or pathologist $(n=46)$, disease confirmation by cytology only $(n=13)$ or refusal of the pathologist to provide archival tissue $(n=7)$. The ITT study population consisted of 274 eligible patients, and 206 patients were eligible for the translational population; detailed patient characteristics are summarised in Table 1. With regard to important baseline parameters (e.g. age, gender, stage of disease, performance status), no significant imbalances between the ITT population and the translational study population were apparent.

Frequency of alternations in molecular EGFR pathway biomarkers. Within Table 2, each of the six analysed markers was categorised as a dichotomous variable and a correlation between selected baseline patient characteristics and molecular marker results were performed.

KRAS exon 2 mutations (codon 12 and 13). The KRAS mutation analysis was technically successful in 173 cases, and a KRAS wildtype was detected in 52 FFPE tumour samples (30\%). All mutations were within codon 12 , with c.35G $>$ A-p.G12D $(n=82$ out of $121,68 \%)$ and c.35G $>$ T-p.G12V ( $n=26$ out of $121,22 \%)$ being the two most frequent mutations observed. The distribution of clinical patient characteristics did not differ significantly between the two subgroups of KRAS mutation and KRAS wildtype (Table 2); however, the median pre-treatment CA 19-9 level was significantly higher $(P=0.03)$ in the KRAS mutant compared with the KRAS wild-type subgroup.

Expression by IHC and fluorescence in-situ hybridisation. EGFR-IHC was successfully performed in 181 cases, with 89 cases (49\%) being classified as EGFR-IHC positive. The EGFR gene amplification was analysed in 166 patients, 77 (46\%) of them were found to have an EGFR gene overexpression by FISH (EGFR-FISH positive). No correlation between EGFR-IHC and -FISH results was observed ( $P=0.97$; detailed data not shown). The distribution of relevant baseline characteristics between the two subgroups of EGFR-IHC positive $v s$ EGFR-IHC negative and EGFR-FISH positive $v s$ EGFR-FISH negative is summarised in Table 2, respectively.

The PTEN expression by IHC. The PTEN-IHC data were obtained from 171 patients, and a loss of PTEN (score 0-3) was detected in 30 cases (18\%). A detailed distribution of the results for the continuous PTEN score (0-6) is included in Table 4.

Epidermal growth factor receptor intron 1 PM. The median number of CA repeats (sum of both alleles) in intron 1 of the EGFR gene was 34 (186 evaluable patients), with a range from 28 to 41 . For dichotomising the EGFR intron 1 variable, we applied the previously reported cutoff point of 36 (according to Tzeng et al, 2007a; Frolov et al, 2010; Table 2). No significant correlation between the EGFR expression by IHC $(P=0.26)$ or FISH $(P=0.31)$ and the EGFR intron $1 \mathrm{PM}$ was observed (data not shown).

Epidermal growth factor receptor exon 13 R497K PM. In 194 patient samples, the analysis of the EGFR R497K PM was technically successful: $112(58 \%)$ showed the GG wild-type sequence, whereas 82 had either the GA or AA SNP. Also, for the exon $13 \mathrm{PM}$, no correlation with the EGFR expression by either IHC $(P=0.80)$ or FISH $(P=0.39)$ was apparent (data not shown). 
Table 1. Baseline patient characteristics: Intention-to-treat population $(n=274)$ and translational study population $(n=206)$

\begin{tabular}{|c|c|c|c|c|c|c|c|c|}
\hline \multirow[b]{3}{*}{ Parameter } & \multicolumn{4}{|c|}{ Intention-to-treat } & \multicolumn{4}{|c|}{ Translational } \\
\hline & \multicolumn{2}{|c|}{ Gem $+E=>$ Cap $(n=143)$} & \multicolumn{2}{|c|}{ Cap $+E=>\operatorname{Gem}(n=131)$} & \multicolumn{2}{|c|}{ Gem $+E=>$ Cap $(n=113)$} & \multicolumn{2}{|c|}{ Cap $+E=>$ Gem $(n=93)$} \\
\hline & No. & $\%$ & No. & $\%$ & No. & $\%$ & No. & $\%$ \\
\hline \multicolumn{9}{|l|}{ Age (years) } \\
\hline $\begin{array}{l}\text { Median } \\
\text { Range }\end{array}$ & $\begin{array}{c}65 \\
32-78\end{array}$ & & $\begin{array}{c}63 \\
38-75\end{array}$ & & $\begin{array}{c}65 \\
32-75\end{array}$ & & $\begin{array}{c}64 \\
42-75\end{array}$ & \\
\hline \multicolumn{9}{|l|}{ Gender } \\
\hline $\begin{array}{l}\text { Male } \\
\text { Female }\end{array}$ & $\begin{array}{l}82 \\
61\end{array}$ & $\begin{array}{l}57 \\
43\end{array}$ & $\begin{array}{l}83 \\
48\end{array}$ & $\begin{array}{l}63 \\
37\end{array}$ & $\begin{array}{l}64 \\
49\end{array}$ & $\begin{array}{l}57 \\
43\end{array}$ & $\begin{array}{l}58 \\
35\end{array}$ & $\begin{array}{l}62 \\
38\end{array}$ \\
\hline \multicolumn{9}{|l|}{ Stage of disease } \\
\hline $\begin{array}{l}\text { Locally advanced } \\
\text { Metastatic }\end{array}$ & $\begin{array}{c}21 \\
122\end{array}$ & $\begin{array}{l}15 \\
85\end{array}$ & $\begin{array}{c}22 \\
109\end{array}$ & $\begin{array}{l}17 \\
83\end{array}$ & $\begin{array}{l}17 \\
96\end{array}$ & $\begin{array}{l}15 \\
85\end{array}$ & $\begin{array}{l}16 \\
77\end{array}$ & $\begin{array}{l}17 \\
83\end{array}$ \\
\hline \multicolumn{9}{|c|}{ Performance status } \\
\hline $\begin{array}{l}\text { KPS 60-80\% } \\
\text { KPS 90-100\% } \\
\text { Missing } \\
\text { Previous surgery }\end{array}$ & $\begin{array}{c}50 \\
85 \\
8 \\
8\end{array}$ & $\begin{array}{c}35 \\
59 \\
6 \\
6\end{array}$ & $\begin{array}{c}49 \\
79 \\
3 \\
17\end{array}$ & $\begin{array}{c}33 \\
60 \\
2 \\
13\end{array}$ & $\begin{array}{c}37 \\
70 \\
6 \\
7\end{array}$ & $\begin{array}{c}33 \\
62 \\
5 \\
6\end{array}$ & $\begin{array}{c}38 \\
55 \\
0 \\
13\end{array}$ & $\begin{array}{c}41 \\
59 \\
0 \\
14\end{array}$ \\
\hline \multicolumn{9}{|c|}{ Weight loss during 3 months before randomisation $(\mathrm{kg})$} \\
\hline $\begin{array}{l}\text { Median } \\
\text { Range }\end{array}$ & $\begin{array}{c}5 \\
0-47\end{array}$ & & $\begin{array}{c}7 \\
0-45\end{array}$ & & $\begin{array}{c}5 \\
0-47\end{array}$ & & $\begin{array}{c}7 \\
0-45\end{array}$ & \\
\hline \multicolumn{9}{|c|}{ Baseline CA 19-9 $\left(\mathrm{U} \mathrm{ml}^{-1}\right)^{\mathrm{a}}$} \\
\hline $\begin{array}{l}\text { Median } \\
\text { Range }\end{array}$ & $\begin{array}{c}1999 \\
1-700000\end{array}$ & & $\begin{array}{c}1756 \\
1-1000000\end{array}$ & & $\begin{array}{c}1999 \\
1-700000\end{array}$ & & $\begin{array}{c}1565 \\
1-1000000\end{array}$ & \\
\hline \multicolumn{9}{|l|}{ TTF1 (months) } \\
\hline $\begin{array}{l}\text { Median } \\
P \text {-value }\end{array}$ & $\begin{array}{c}3.2 \\
P=0.0034\end{array}$ & & 2.2 & & $\begin{array}{c}3.2 \\
P=0.0089^{b}\end{array}$ & & 2.2 & \\
\hline \multicolumn{9}{|l|}{ TTF2 (months) } \\
\hline $\begin{array}{l}\text { Median } \\
P \text {-value }\end{array}$ & $\begin{array}{c}4.2 \\
P=1.0\end{array}$ & & 4.2 & & $\begin{array}{c}4.1 \\
P=0.85^{b}\end{array}$ & & 4.0 & \\
\hline \multicolumn{9}{|l|}{ OS (months) } \\
\hline Median & 6.2 & & 6.9 & & 5.7 & & 6.7 & \\
\hline$P$-value & $P=0.90$ & & & & $P=0.57^{b}$ & & & \\
\hline $\begin{array}{l}\text { Abbreviations: Cap }= \\
\text { TTF2 }=\text { time-to-treatn } \\
a_{n}=245 \text { out of } 274 . \\
b_{\text {Exploratory analysis }}\end{array}$ & $\begin{array}{l}\text { citabine; } E=\text { erlo } \\
\text { ilure (first-line an }\end{array}$ & $\begin{array}{l}m=\text { gemcit } \\
\text { ine therapy }\end{array}$ & ne; KPS $=$ Karnofs & mance stat & OS $=$ overall su & $\mathrm{F} 1=$ time $-\mathrm{tc}$ & treatment failure & e therapy); \\
\hline
\end{tabular}

Patients with a GG wild-type sequence were more likely to have locally advanced disease compared with patients with a GA or AA SNP (21\% vs 9\%, $P=0.017$; Table 2).

Correlation of molecular EGFR pathway biomarkers with efficacy end points. Table 3 summarises the correlation of biomarker results (as dichotomous variables) with the study end points time-to-treatment failure for first-line (TTF1) and first and second-line therapy (TTF2) as well as OS. A significant correlation with TTF1 and TTF2 was observed for PTEN (HR 0.61, $P=0.02$ and HR $0.66, P=0.04$, respectively). The only biomarker that had a statistically significant impact on OS in this univariate analysis
(HR 1.68, $P=0.005)$ was KRAS; however, no significant difference for TTF1 (HR 1.23, $P=0.22$ ) or TTF2 (HR 1.34, $P=0.09$ ) was observed for patients with a KRAS wild-type $v s$ a KRAS-mutated status, respectively (Table 3). The Kaplan-Meier plot for KRAS and OS is shown in Figure 1. The four biomarkers that were analysable as continuous variables were correlated with TTF1, TTF2 and OS with regard to each of their expression levels (if applicable, the lowest level/score thereby was set as $H R=1$; see Table 4). None of the investigated markers reached the level of statistical significance in these analyses; however a nonsignificantbut at least consistent-trend for a prolonged TTF1, TTF2 and OS was evident for increasing levels of the PTEN score. Of note, none 


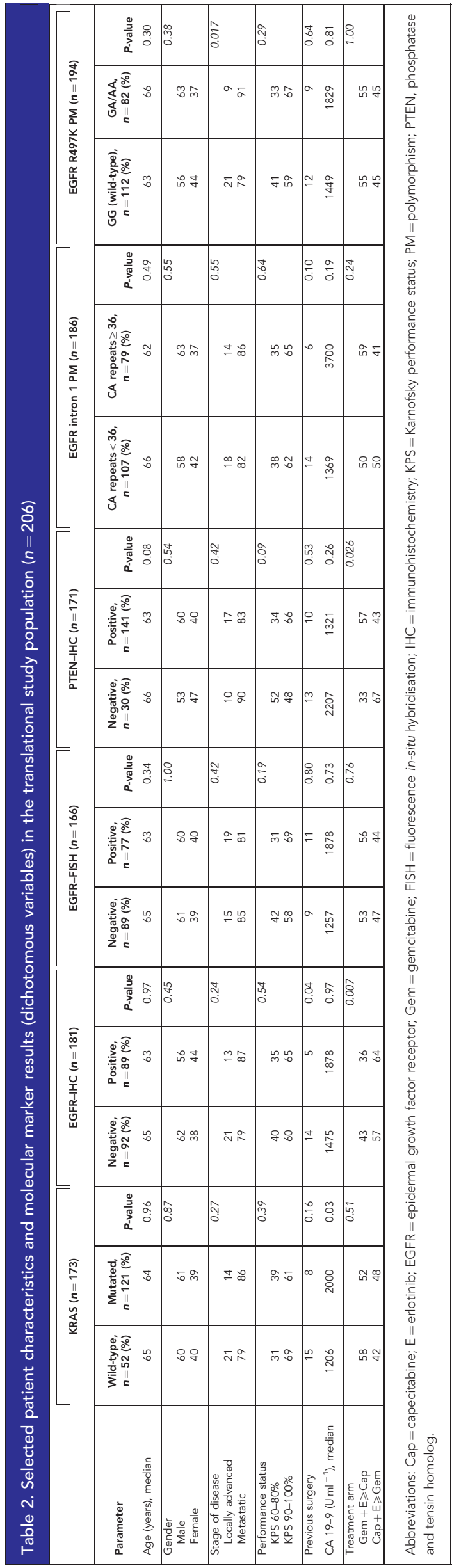

of the six investigated markers showed a significant correlation with objective response (to first-line treatment) as determined by RECIST, version 1.0 (detailed data not shown).

Correlation of molecular EGFR pathway biomarkers with skin rash. None of the six molecular biomarkers correlated with the occurrence of skin rash (any grade I-IV): the corresponding odds ratios for each marker (dichotomous and/or continuous variable, as appropriate) are summarised in Table 5.

\section{DISCUSSION}

AIO-PK0104 is one of the first phase 3 trials in advanced PC that was accompanied by a large translational research project. To date, only limited data on EGFR pathway biomarkers are available for PC, specifically in patients being treated with anti-EGFR agents such as erlotinib or cetuximab. In contrast to the biomarker results of the PA.3 study, we found a higher rate of KRAS wild-type patients within our translational study population (30\% vs $21 \%$ ), and a KRAS wild-type status was the only analysed marker associated with an improved OS in our patient population (Da Cunha Santos et al, 2010). Whether the favourable prognosis of KRAS wild-type patients is a prognostic phenomenon (e.g. independent of erlotinib treatment) or a predictive factor for erlotinib efficacy could not be clarified as erlotinib was applied in both trial arms. However, as there was no significant correlation of either TTF1 or the objective response rate (to first-line therapy) with the KRAS mutational status, one might hypothesisebased on the translational data from the AIO-PK0104 studythat KRAS may rather be a prognostic factor than predictive for erlotinib efficacy. The current KRAS data from the literature on this topic (summarised in detail within Supplementary Table S2) still remain conflicting to some extent, as there are studies that found no correlation at all of KRAS with OS (Da Cunha Santos et al, 2010), whereas others support the assumption that KRAS serves as prognostic biomarker in PC (Lee et al, 2007; Chen et al, 2010; Ogura et al, 2012). In contrast, recent data from a retrospective, non-randomised single-centre analysis suggest that KRAS may rather be a predictive marker for erlotinib efficacy than a prognostic factor; this information obviously needs to be verified by a well-designed prospective study (Kim et al, 2011).

On the basis of our data, no correlation with efficacy end points was found for EGFR-IHC, EGFR-FISH, EGFR intron 1 or exon 13 R497K PM (Table 3). Regarding the expression of PTEN, a trend for a worse outcome with regard to TTF1, TTF2 and OS was apparent for patients with PTEN-deficient tumours (when analysing PTEN as a dichotomous or as a continuous variable, respectively; see Tables 3 and 4). Thus, the loss of the tumoursuppressor PTEN may perhaps represent a prognostically unfavourable event also in PC (Loupakis et al, 2009; Feng et al, 2011). Therefore, one might conclude that the expression of the EGFR itself (determined either by IHC or FISH) does not serve as a relevant biomarker in advanced PC and that future translational research should focus on EGFR downstream signalling networks (such as the PI3K-AKT-PTEN and the RAS-MAPK-MEK-ERK cascade) as prognostic and/or predictive targets in patients treated with anti-EGFR agents. Furthermore, we were not able to confirm data from previous reports, suggesting an association of two EGFR PMs (intron 1 and exon 13 R497K) with efficacy outcome parameters or skin rash, respectively (Wang et al, 2007; Tzeng et al, 2007a; Huang et al, 2009; Sasaki et al, 2009). Of note, most of the existing evidence on the role of these two EGFR PMs was derived from diseases other than PC, and the exciting hypothesis-generating pre-clinical data in PC could-at least in part-not be transferred into the clinical setting (Tzeng et al, 2007a; Frolov et al, 2010). 
Table 3. Correlation of biomarker results (dichotomous variables) with efficacy parameters: TTF1, TTF2 and OS

\begin{tabular}{|c|c|c|c|c|c|c|c|c|c|c|}
\hline & & \multicolumn{3}{|c|}{ Median TTF1 } & \multicolumn{3}{|c|}{ Median TTF2 } & \multicolumn{3}{|c|}{ Median OS } \\
\hline Biomarker (alteration) & $n$ & Mo. & $\mathrm{HR}(95 \% \mathrm{Cl})$ & $P$ & Mo. & $\mathrm{HR}(95 \% \mathrm{Cl})$ & $P$ & Mo. & $\mathrm{HR}(95 \% \mathrm{Cl})$ & $P$ \\
\hline $\begin{array}{l}\text { KRAS } \\
\text { Wild type } \\
\text { Mutation }\end{array}$ & $\begin{array}{r}173 \\
52 \\
121\end{array}$ & $\begin{array}{l}2.9 \\
2.2\end{array}$ & $1.23(0.88-1.71)$ & 0.22 & $\begin{array}{l}4.2 \\
4\end{array}$ & $1.34(0.96-1.87)$ & 0.09 & $\begin{array}{l}7.9 \\
5.7\end{array}$ & $1.68(1.17-2.41)$ & 0.005 \\
\hline $\begin{array}{l}\text { EGFR-IHC } \\
\text { Negative } \\
\text { Positive }\end{array}$ & $\begin{array}{r}181 \\
92 \\
89\end{array}$ & $\begin{array}{l}2.2 \\
3.1\end{array}$ & $0.76(0.56-1.02)$ & 0.07 & $\begin{array}{l}3.9 \\
4.1\end{array}$ & $0.82(0.60-1.11)$ & 0.19 & $\begin{array}{l}6.7 \\
6.9\end{array}$ & $0.96(0.71-1.31)$ & 0.8 \\
\hline $\begin{array}{l}\text { EGFR-FISH } \\
\text { Negative } \\
\text { Positive }\end{array}$ & $\begin{array}{r}166 \\
89 \\
77\end{array}$ & $\begin{array}{l}2.5 \\
2.8\end{array}$ & $0.90(0.66-1.23)$ & 0.51 & $\begin{array}{l}4.1 \\
4.1\end{array}$ & $1.03(0.75-1.42)$ & 0.84 & $\begin{array}{l}6.9 \\
6.7\end{array}$ & $1.22(0.87-1.70)$ & 0.25 \\
\hline $\begin{array}{l}\text { PTEN-IHC } \\
\text { Negative } \\
\text { Positive }\end{array}$ & $\begin{array}{r}171 \\
30 \\
141\end{array}$ & $\begin{array}{l}2 \\
2.4\end{array}$ & $0.61(0.41-0.92)$ & 0.02 & $\begin{array}{l}3 \\
4.1\end{array}$ & $0.66(0.44-0.98)$ & 0.04 & $\begin{array}{l}4.5 \\
6.8\end{array}$ & $0.77(0.51-1.17)$ & 0.22 \\
\hline $\begin{array}{r}\text { EGFR intron } 1 \text { PM } \\
\text { CA repeats }<36 \\
\text { CA repeats } \geqslant 36\end{array}$ & $\begin{array}{r}186 \\
107 \\
79\end{array}$ & $\begin{array}{l}2.6 \\
2.8\end{array}$ & $0.91(0.67-1.22)$ & 0.52 & $\begin{array}{l}4.1 \\
4.4\end{array}$ & $0.84(0.62-1.14)$ & 0.25 & $\begin{array}{l}6.7 \\
6.9\end{array}$ & $0.91(0.67-1.24)$ & 0.55 \\
\hline $\begin{array}{l}\text { EGFR R497K PM } \\
\text { GG } \\
\text { GA/AA }\end{array}$ & $\begin{array}{r}194 \\
112 \\
82 \\
\end{array}$ & $\begin{array}{l}2.4 \\
2.8\end{array}$ & $0.88(0.65-1.18)$ & 0.38 & $\begin{array}{l}4.1 \\
4.2\end{array}$ & $0.90(0.67-1.21)$ & 0.48 & $\begin{array}{l}5.8 \\
7.3\end{array}$ & $0.83(0.61-1.13)$ & 0.23 \\
\hline
\end{tabular}

Abbreviations: $\mathrm{Cl}=$ confidence interval; $\mathrm{FISH}=$ fluorescence in-situ hybridisation; $\mathrm{HR}=$ hazard ratio; $I \mathrm{HC}=$ immunohistochemistry; $\mathrm{Mo}$. = months; OS=overall survival; $\mathrm{PM}=$ polymorphism; TTF1 = time-to-treatment failure 1; TTF2 = time-to-treatment failure 2.

Table 4. Correlation of selected biomarker results (analysable as continuous variables) with efficacy parameters: TTF1, TTF2, and OS

\begin{tabular}{|c|c|c|c|c|c|c|c|}
\hline \multirow[b]{2}{*}{ Biomarker (alteration) } & \multirow[b]{2}{*}{$n$} & \multicolumn{2}{|c|}{ TTF1 } & \multicolumn{2}{|c|}{ TTF2 } & \multicolumn{2}{|l|}{ os } \\
\hline & & $\mathrm{HR}(95 \% \mathrm{Cl})$ & $\boldsymbol{P}$ & $\mathrm{HR}(95 \% \mathrm{Cl})$ & $\boldsymbol{P}$ & $\mathrm{HR}(95 \% \mathrm{Cl})$ & $\boldsymbol{P}$ \\
\hline EGFR-IHC score & 181 & & & & & & \\
\hline 0 & 7 & 1 & & 1 & & 1 & \\
\hline 1 & 85 & $0.91(0.42-1.97)$ & & $0.92(0.43-2.00)$ & & $1.03(0.47-2.25)$ & \\
\hline 2 & 48 & $0.63(0.28-1.40)$ & & $0.70(0.31-1.55)$ & & $0.84(0.38-1.88)$ & \\
\hline 3 & 41 & $0.79(0.35-1.78)$ & 0.22 & $0.85(0.38-1.92)$ & 0.48 & $1.21(0.54-2.73)$ & 0.46 \\
\hline EGFR-FISH score & 166 & & & & & & \\
\hline Trisomy low & 4 & 1 & & 1 & & 1 & \\
\hline Trisomy high & 23 & $0.77(0.27-2.25)$ & & $1.07(0.37-3.16)$ & & $2.36(0.66-8.36)$ & \\
\hline Polysomy low & 62 & $0.81(0.29-2.24)$ & & $1.59(0.57-4.42)$ & & $3.01(0.89-10.14)$ & \\
\hline Polysomy high & 74 & $0.72(0.26-1.98)$ & & $1.43(0.52-3.97)$ & & $3.28(0.96-11.19)$ & \\
\hline Amplification & 3 & $0.92(0.17-5.07)$ & 0.94 & $1.43(0.26-7.87)$ & 0.59 & $2.72(0.27-27.26)$ & 0.28 \\
\hline PTEN-IHC score & 171 & & & & & & \\
\hline 0 & 16 & 1 & & 1 & & 1 & \\
\hline 1 & 0 & - & & - & & - & \\
\hline 2 & 7 & $0.77(0.32-1.89)$ & & $0.69(0.28-1.68)$ & & $0.87(0.34-2.24)$ & \\
\hline 3 & 7 & $0.75(0.31-1.84)$ & & $0.61(0.25-1.50)$ & & $0.87(0.34-2.23)$ & \\
\hline 4 & 95 & $0.59(0.34-1.01)$ & & $0.59(0.34-1.02)$ & & $0.84(0.49-1.43)$ & \\
\hline 5 & 36 & $0.45(0.24-0.83)$ & & $0.43(0.23-0.79)$ & & $0.60(0.32-1.11)$ & \\
\hline 6 & 10 & $0.37(0.17-0.83)$ & 0.09 & $0.34(0.15-0.77)$ & 0.07 & $0.38(0.16-0.88)$ & 0.17 \\
\hline EGFR intron 1 PM & 186 & $1.01(0.95-1.07)$ & 0.7 & $1.00(0.94-1.06)$ & 0.93 & $1.02(0.96-1.08)$ & 0.54 \\
\hline
\end{tabular}

One main limitation for translational research in PC arises from the fact that histological tumour tissue often is insufficient for detailed molecular analyses. Furthermore, different methods often require a sufficient amount of adequate tissue/tumour cells (e.g. FISH analyses), and thus it remains a challenge to obtain a full analysis data set with complete results for all tissue samples submitted to molecular analysis. We were able to obtain archival FFPE tissue from 208 of the 281 randomised patients; however, the overall sample size of our 'complete biomarker measurements set' was 138 patients only. These aspects on tissue quality and technical 


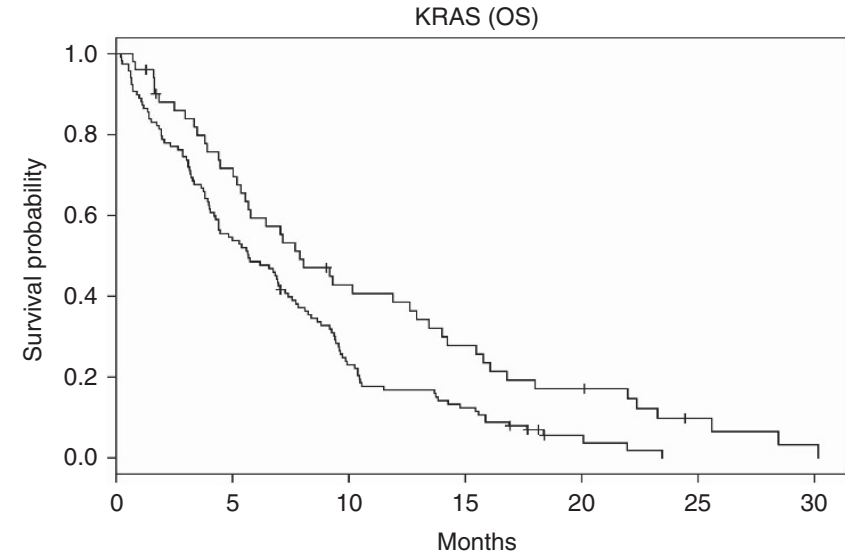

Figure 1. Correlation between KRAS mutation status and OS. $(n=173$, 157 events). Black line, KRAS wild-type, Grey line, KRAS mutation.

Table 5. Correlation of molecular EGFR pathway biomarkers with the occurrence of skin rash (any grades, I-IV)

\begin{tabular}{|l|c|c|c|c|c|}
\cline { 4 - 6 } & \multicolumn{3}{c|}{$\begin{array}{c}\text { Dichotomous } \\
\text { variable }\end{array}$} & \multicolumn{2}{c|}{$\begin{array}{c}\text { Continuous } \\
\text { variable }\end{array}$} \\
\hline Biomarker & $\boldsymbol{n}$ & Odds ratio & $\boldsymbol{P}$ & Odds ratio & $\boldsymbol{P}$ \\
\hline KRAS & 163 & 0.96 & 0.59 & - & \\
\hline EGFR-IHC & 170 & 1.09 & 0.22 & $0.97^{\mathrm{a}}$ & $0.37^{\text {a }}$ \\
\hline EGFR-FISH & 155 & 1.03 & 0.73 & $1.18^{\text {a }}$ & $0.74^{\text {a }}$ \\
\hline PTEN-IHC & 161 & 0.91 & 0.33 & $1.09^{\text {a }}$ & $0.42^{\text {a }}$ \\
\hline EGFR intron 1 PM & 176 & 0.93 & 0.29 & 0.99 & 0.31 \\
\hline EGFR R497K PM & 182 & 1.1 & 0.19 & - & \\
\hline $\begin{array}{l}\text { Abbreviations: EGFR = epidermal growth factor receptor; FISH=fluorescence in-situ } \\
\text { hybridisation; IHC=immunohistochemistry; KRAS = Kirsten rat sarcoma viral oncogene; } \\
\text { PM = polymorphism; PTEN = Phosphatase and tensin homolog. } \\
\text { a Single odds ratio for lowest vs highest score; global P-value. }\end{array}$ \\
\hline
\end{tabular}

performance thus also might significantly affect biostatistical results; this potential bias also was the main reason why the authors decided not to perform multivariate analyses within this explorative investigation.

Skin rash as a frequent side-effect developing during erlotinib treatment is known to correlate with a longer survival in advanced PC (Moore et al, 2007). Thus, a molecular marker that could serve as a (pre-treatment) predictor for rash would be a valuable tool for treatment selection. However, none of the six EGFR pathway biomarker analyses within this translational substudy showed a correlation with the occurrence of rash (Table 5).

The question arises how to move forward in PC translational research: most of the data that increased our understanding of molecular resistance and molecular predictors for efficacy of antiEGFR agents were derived from well-conducted trials in CRC and NSCLC (De Roock et al, 2010; Wheeler et al, 2010). Nevertheless, a translation of these results into PC will not be appropriate, mainly because of the fact that PC represents a genetically complex malignancy, which is based on multifactorial aberrations. Besides the EGFR pathway, molecular predictors for the efficacy of cytotoxic agents such as gemcitabine (e.g. hENT1) seem promising and a new avenue of research also identified peritumoral stroma (e.g. SPARC) as a relevant target in PC treatment (Farrell et al, 2009; Von Hoff et al, 2011). Most importantly, translational research projects should be included in all well-designed ongoing and future PC trials: only with a prospective collection of adequate tissue, the use of standardised and comparable molecular methods and innovative biostatistical models prognostic and/or predictive biomarkers may also be established in PC.

In conclusion, the explorative translational substudy on AIOPK0104 demonstrated that translational research with FFPE tumour tissue is feasible also in PC multicenter phase 3 trials and that KRAS and PTEN may have a role as biomarkers associated with treatment outcome in erlotinib-treated patients with advanced PC. Validation of these results within other PC randomised trials (investigating anti-EGFR and other novel targeted and cytotoxic agents) is urgently awaited.

\section{ACKNOWLEDGEMENTS}

We thank all patients and their families, nurses, study coordinators and investigators for their participation in the AIO-PK0104 study. In addition, the active commitment of the pathologists providing FFPE archival tumour tissue is gratefully acknowledged because they enabled this translational study. This study was funded by Roche Pharma AG, Germany and Sturm-Stiftung, City of Munich, Germany.

\section{CONFLICT OF INTEREST}

Stefan Boeck and Michael $\mathrm{R}$ Clemens received Honoraria for scientific presentations, Research funding and Travel grants from Roche. Volker Heinemann was a consultant in Roche, and received Honoraria for scientific presentations and Research funding from Roche. The remaining authors declare no conflict of interest.

\section{REFERENCES}

Amador ML, Oppenheimer D, Perea S, Maitra A, Cusatis G, IacobuzioDonahue C, Baker SD, Ashfaq R, Takimoto C, Forastiere A, Hidalgo M (2004) An epidermal growth factor receptor intron 1 polymorphism mediates response to epidermal growth factor receptor inhibitors. Cancer Res 64(24): 9139-9143.

Boeck S, Hinke A, Wilkowski R, Heinemann V (2007) Importance of performance status for treatment outcome in advanced pancreatic cancer. World J Gastroenterol 13(2): 224-227.

Boeck S, Haas M, Laubender RP, Kullmann F, Klose C, Bruns CJ, Wilkowski R, Stieber P, Holdenrieder S, Buchner H, Mansmann U, Heinemann V (2010) Application of a time-varying covariate model to the analysis of CA 19-9 as serum biomarker in patients with advanced pancreatic cancer. Clin Cancer Res 16(3): 986-994.

Cappuzzo F, Hirsch FR, Rossi E, Bartolini S, Ceresoli GL, Bemis L, Haney J, Witta S, Danenberg K, Domenichini I, Ludovini V, Magrini E, Gregorc V, Doglioni C, Sidoni A, Tonato M, Franklin WA, Crino L, Bunn Jr PA, Varella-Garcia M (2005) Epidermal growth factor receptor gene and protein and gefitinib sensitivity in non-small-cell lung cancer. J Natl Cancer Inst 97(9): 643-655.

Chen H, Tu H, Meng ZQ, Chen Z, Wang P, Liu LM (2010) K-ras mutational status predicts poor prognosis in unresectable pancreatic cancer. Eur $J$ Surg Oncol 36(7): 657-662.

Da Cunha Santos G, Dhani N, Tu D, Chin K, Ludkovski O, Kamel-Reid S, Squire J, Parulekar W, Moore MJ, Tsao MS (2010) Molecular predictors of outcome in a phase 3 study of gemcitabine and erlotinib therapy in patients with advanced pancreatic cancer: National Cancer Institute of Canada Clinical Trials Group Study PA.3. Cancer 116(24): 5599-5607.

De Roock W, Jonker DJ, Di Nicolantonio F, Sartore-Bianchi A, Tu D, Siena S, Lamba S, Arena S, Frattini M, Piessevaux H, Van Cutsem E, O'Callaghan CJ, Khambata-Ford S, Zalcberg JR, Simes J, Karapetis CS, Bardelli A, Tejpar S (2010) Association of KRAS p.G13D mutation with outcome in patients with chemotherapy-refractory metastatic colorectal cancer treated with cetuximab. JAMA 304(16): 1812-1820.

Farrell JJ, Elsaleh H, Garcia M, Lai R, Ammar A, Regine WF, Abrams R, Benson AB, Macdonald J, Cass CE, Dicker AP, Mackey JR (2009) Human equilibrative nucleoside transporter 1 levels predict response to 
gemcitabine in patients with pancreatic cancer. Gastroenterology 136(1): $187-195$.

Feng C, Yao R, Huang F, Liu X, Nie W (2011) High level of PTEN expression and its association with low-grade liver metastases and satisfactory patient survival in pancreatic cancer. Arch Med Res 42(7): 584-588.

Frolov A, Liles JS, Kossenkov AV, Tzeng CW, Jhala N, Kulesza P, Varadarajulu S, Eloubeidi M, Heslin MJ, Arnoletti JP (2010) Epidermal growth factor receptor (EGFR) intron 1 polymorphism and clinical outcome in pancreatic adenocarcinoma. Am J Surg 200(3): 398-405.

Heinemann V, Stintzing S, Kirchner T, Boeck S, Jung A (2009) Clinical relevance of EGFR- and KRAS-status in colorectal cancer patients treated with monoclonal antibodies directed against the EGFR. Cancer Treat Rev 35(3): 262-271.

Heinemann V, Vehling-Kaiser U, Waldschmidt D, Kettner E, Märten A, Winkelmann C, Klein S, Kojouharoff G, Gauler TC, Fischer von Weikersthal L, Clemens MR, Geissler M, Greten TF, Hegewisch-Becker S, Rubanov O, Baake G, Höhler T, Ko YD, Jung A, Neugebauer S, Boeck S (2012) Gemcitabine plus erlotinib followed by capecitabine versus capecitabine plus erlotinib followed by gemcitabine in advanced pancreatic cancer: final results of a randomised phase 3 trial of the 'Arbeitsgemeinschaft Internistische Onkologie' (AIO-PK0104). Gut; e-pub ahead of print.

Heist RS, Christiani D (2009) EGFR-targeted therapies in lung cancer: predictors of response and toxicity. Pharmacogenomics 10(1): 59-68.

Huang CL, Yang CH, Yeh KH, Hu FC, Chen KY, Shih JY, Lin ZZ, Yu CJ, Cheng AL, Yang PC (2009) EGFR intron 1 dinucleotide repeat polymorphism is associated with the occurrence of skin rash with gefitinib treatment. Lung Cancer 64(3): 346-351.

Immervoll H, Hoem D, Kugarajh K, Steine SJ, Molven A (2006) Molecular analysis of the EGFR-RAS-RAF pathway in pancreatic ductal adenocarcinomas: lack of mutations in the BRAF and EGFR genes. Virchows Arch 448(6): 788-796.

Kim ST, Lim do H, Jang KT, Lim T, Lee J, Choi YL, Jang HL, Yi JH, Baek KK, Park SH, Park YS, Lim HY, Kang WK, Park JO (2011) Impact of KRAS mutations on clinical outcomes in pancreatic cancer patients treated with first-line gemcitabine-based chemotherapy. Mol Cancer Ther 10(10): 1993-1999.

Klinghammer K, Knödler M, Schmittel A, Budach V, Keilholz U, Tinhofer I (2010) Association of epidermal growth factor receptor polymorphism, skin toxicity, and outcome in patients with squamous cell carcinoma of the head and neck receiving cetuximab-docetaxel treatment. Clin Cancer Res 16(1): 304-310.

Lee J, Jang KT, Ki CS, Lim T, Park YS, Lim HY, Choi DW, Kang WK, Park K, Park JO (2007) Impact of epidermal growth factor receptor (EGFR) kinase mutations, EGFR gene amplifications, and KRAS mutations on survival of pancreatic adenocarcinoma. Cancer 109(8): 1561-1569.

Loupakis F, Pollina L, Stasi I, Ruzzo A, Scartozzi M, Santini D, Masi G, Graziano F, Cremolini C, Rulli E, Canestrari E, Funel N, Schiavon G, Petrini I, Magnani M, Tonini G, Campani D, Floriani I, Cascinu S, Falcone A (2009) PTEN expression and KRAS mutations on primary tumors and metastases in the prediction of benefit from cetuximab plus irinotecan for patients with metastatic colorectal cancer. J Clin Oncol 27(16): $2622-2629$.

Moore MJ, Goldstein D, Hamm J, Figer A, Hecht JR, Gallinger S, Au HJ, Murawa P, Walde D, Wolff RA, Campos D, Lim R, Ding K, Clark G, Voskoglou-Nomikos T, Ptasynski M, Parulekar W (2007) Erlotinib plus gemcitabine compared with gemcitabine alone in patients with advanced pancreatic cancer. A phase III trial of the National Cancer Institute of Canada Clinical trials group. J Clin Oncol 25(15): 1960-1966.
Neumann J, Zeindl-Eberhart E, Kirchner T, Jung A (2009) Frequency and type of KRAS mutations in routine diagnostic analysis of metastatic colorectal cancer. Pathol Res Pract 205(12): 858-862.

Ng SS, Tsao MS, Nicklee T, Hedley DW (2002) Effects of the epidermal growth factor receptor inhibitor OSI-774, Tarceva, on downstream signaling pathways and apoptosis in human pancreatic adenocarcinoma. Mol Cancer Ther 1(10): 777-783.

Ogura T, Yamao K, Hara K, Mizuno N, Hijioka S, Imaoka H, Sawaki A, Niwa Y, Tajika M, Kondo S, Tanaka T, Shimizu Y, Bhatia V, Higuchi K, Hosoda W, Yatabe Y (2012) Prognostic value of K-ras mutation status and subtypes in endoscopic ultrasound-guided fine-needle aspiration specimens from patients with unresectable pancreatic cancer. J Gastroenterol; e-pub ahead of print.

Pirker R, Pereira JR, von Pawel J, Krzakowski M, Ramlau R, Park K, de Marinis F, Eberhardt WE, Paz-Ares L, Störkel S, Schumacher KM, von Heydebreck A, Celik I, O'Byrne KJ (2012) EGFR expression as a predictor of survival for first-line chemotherapy plus cetuximab in patients with advanced non-small-cell lung cancer: analysis of data from the phase 3 FLEX study. Lancet Oncol 13(1): 33-42.

Sasaki H, Okuda K, Shimizu S, Takada M, Kawahara M, Kitahara N, Okumura M, Matsumura A, Iuchi K, Kawaguchi T, Kubo A, Kawano O, Yukiue H, Yano M, Fujii Y (2009) EGFR R497K polymorphism is a favorable prognostic factor for advanced lung cancer. J Cancer Res Clin Oncol 135(2): 313-318.

Stathis A, Moore MJ (2010) Advanced pancreatic carcinoma: current treatment and future challenges. Nat Rev Clin Oncol 7(3): 163-172.

Tzeng CW, Frolov A, Frolova N, Jhala NC, Howard JH, Vickers SM, Buchsbaum DJ, Heslin MJ, Arnoletti JP (2007a) Pancreatic cancer epidermal growth factor receptor (EGFR) intron 1 polymorphism influences postoperative patient survival and in vitro erlotinib response. Ann Surg Oncol 14(7): 2150-2158.

Tzeng CW, Frolov A, Frolova N, Jhala NC, Howard JH, Vickers SM, Buchsbaum DJ, Heslin MJ, Arnoletti JP (2007b) EGFR genomic gain and aberrant pathway signaling in pancreatic cancer patients. J Surg Res 143(1): 20-26.

Ueda S, Ogata S, Tsuda H, Kawarabayashi N, Kimura M, Sugiura Y, Tamai S, Matsubara O, Hatsuse K, Mochizuki H (2004) The correlation between cytoplasmic overexpression of epidermal growth factor receptor and tumor aggressiveness: poor prognosis in patients with pancreatic ductal adenocarcinoma. Pancreas 29(1): e1-e8.

Von Hoff DD, Ramanathan RK, Borad MJ, Laheru DA, Smith LS, Wood TE, Korn RL, Desai N, Trieu V, Iglesias JL, Zhang H, Soon-Shiong P, Shi T, Rajeshkumar NV, Maitra A, Hidalgo M (2011) Gemcitabine plus nab-paclitaxel is an active regimen in patients with advanced pancreatic cancer: a phase I/II trial. J Clin Oncol 29(34): 4548-4554.

Wang WS, Chen PM, Chiou TJ, Liu JH, Lin JK, Lin TC, Wang HS, Su Y (2007) Epidermal growth factor receptor R497K polymorphism is a favorable prognostic factor for patients with colorectal carcinoma. Clin Cancer Res 13(12): 3597-3604.

Wheeler DL, Dunn EF, Harari PM (2010) Understanding resistance to EGFR inhibitors-impact on future treatment strategies. Nat Rev Clin Oncol 7(9): 493-507.

This work is published under the standard license to publish agreement. After 12 months the work will become freely available and the license terms will switch to a Creative Commons AttributionNonCommercial-Share Alike 3.0 Unported License.

Supplementary Information accompanies this paper on British Journal of Cancer website (http://www.nature.com/bjc) 